\title{
Formulation, preparation and in vitro-in vivo evaluation of compression-coated tablets for the colonic-specific release of ketoprofen
}

\author{
Dana Hales ${ }^{1}$, Dan Lucian Dumitrașcu², Ioan Tomuță ${ }^{1 *}$, Corina Briciu ${ }^{3}$, Dana-Maria Muntean ${ }^{1}$, \\ Lucia Ruxandra Tefas ${ }^{1}$, Sonia Iurian ${ }^{1}$, Rareș Iuliu Iovanov ${ }^{1}$, Marcela Achim ${ }^{1}$, Laurian Vlase ${ }^{1}$
}

\begin{abstract}
${ }^{1}$ Department of Pharmaceutical Technology and Biopharmacy, Faculty of Pharmacy, University of Medicine and Pharmacy “Iuliu Hațieganu”, Cluj-Napoca, Cluj, Romania, ${ }^{2}$ Department of Medical Clinic II, Internal Medicine, Faculty of Medicine, University of Medicine and Pharmacy "Iuliu Hațieganu”, Cluj-Napoca, Cluj, Romania, ${ }^{3}$ Department of Clinical Pharmacy, Faculty of Pharmacy, University of Medicine and Pharmacy “Iuliu Hațieganu”, Cluj-Napoca, Cluj, Romania
\end{abstract}

\begin{abstract}
The aim of this study was to formulate and prepare compression-coated tablets for colonic release (CR-tablets), and to evaluate the bioavailability of ketoprofen following the administration of a single dose from mini-tablets with immediate release (IR-tablets) compared to CR-tablets. CR-tablets were prepared based on time-controlled hydroxypropylmethylcellulose K100M inner compression-coating and $\mathrm{pH}$-sensitive Eudragit ${ }^{\mathbb{R}}$ L 30D-55 outer film-coating. The clinical bioavailability study consisted of two periods, in which two formulations were administered to 6 volunteers, according to a randomized cross-over design. The apparent cumulative absorption amount of ketoprofen was estimated by plasma profile deconvolution. CR-tablets were able to delay ketoprofen's release. Compared to IR-tablets used as reference, for the CR-tablets the maximum plasma concentration $\left(C_{\max }\right)$ was lower $(4920.33 \pm 1626.71$ $\mathrm{ng} / \mathrm{mL}$ vs. $9549.50 \pm 2156.12 \mathrm{ng} / \mathrm{mL}$ for IR-tablets) and the time needed to reach $\mathrm{C}_{\max }\left(\mathrm{t}_{\max }\right)$ was $5.33 \pm 1.63$ $\mathrm{h}$ for CR-tablets vs. $1.33 \pm 0.88 \mathrm{~h}$ for IR-tablets. In vitro-in vivo comparison of the apparent cumulative absorption amount of ketoprofen showed similar values for the two formulations. Therefore, the obtained pharmacokinetic parameters and the in vitro-in vivo comparison demonstrated the reliability of the developed pharmaceutical system and the fact that it is able to avoid the release of ketoprofen in the first part of the digestive tract.
\end{abstract}

Keywords: Colonic delivery. Compression-coated tablets. pH-Dependent release. Time-dependent release. In vitro-in vivo comparison.

\section{INTRODUCTION}

A particular type of pharmaceutical system for colonic release is the chronopharmaceutical system with pulsatile release. The use of pulsatile release systems may be advantageous for adapting the treatment to chronopharmacological needs (for example, in the treatment of cardiovascular diseases, asthma, arthritis, ulcers) (Biswas et al., 2015; Vonica, Tomuță, Leucuța, 2011) or to target a drug to a specific site in the digestive tract, for example in the colon (Hashem et al., 2011;

\footnotetext{
*Correspondence: I. Tomuță. Department of Pharmaceutical Technology and Biopharmacy, Faculty of Pharmacy, University of Medicine and Pharmacy "Iuliu Hatieganu", Cluj-Napoca, 41 Victor Babeș Street, 400012 Cluj-Napoca, Romania. E-mail: tomutaioan@umfcluj.ro
}

Veerareddy, Vemula, 2012). Chronotherapeutical systems include among them the compression-coated tablets. The drug core of compression-coated tablets is usually represented by a mini-tablet which offers the advantages of reduced size, regular shape and smooth surface, thus providing excellent support for coating with various polymers.

Compression-coated tablets as colonic release systems are usually obtained by coating the drug cores by compression-coating (Fukui, Miyamura, Kobayashi, 2001a, 2001b; Fukui et al., 2001). Very few works were found to prepared colon delivery systems by doublecompression coating (Vemula, 2015) or by compressioncoating combined with film-coating (Fukui et al., 2000). The polymers in the coating layers are usually soluble or insoluble matrix-forming polymers, capable of controling 
drug release by matrix dissolution or erosion (Biswas et al., 2015), polysaccharides which control drug release through their enzymatic degradation by the colonic microflora (Sinha et al., 2004) or enteric polymers, which are insoluble in acidic media, but dissolve in slightly acid to neutral $\mathrm{pH}$ environments (Fukui et al., 2000). The association of two or more approaches has shown superior results regarding colon-specific drug release, namely negligible drug release in the stomach and small intestine and considerable amount of drug released in the colon. Despite the fact that there are several studies regarding chronotherapeutical systems, there is little published information available on colon-specific double-coated tablets based on associating time-controlled and $\mathrm{pH}$ sensitive approaches. Therefore, the present study sought to prepare a new ketoprofen colon-specific compressioncoated tablet system based on the combination of timecontrolled and $\mathrm{pH}$-controlled polymers.

Ketoprofen is a nonsteroidal anti-inflammatory drug (NSAID) indicated mainly for analgesic and antiinflammatory effect in the treatment of pain and rheumatic diseases, respectively (Shohin et al., 2011; Yiyun, Tongwen, Rongqinag, 2005). Ketoprofen is considered a good candidate for colon delivery due to the well known gastric side effects (Maestrelli et al., 2008), as well as to provide the chronotherapy in the treatment of rheumatoid arthritis, a disease influenced by circadian rhythms (Maestrelli et al., 2015). Thus, there are several research works that studied the strategies of oral administration and colon-specific release of ketoprofen. It was included in various pharmaceutical systems, from microparticles (Maestrelli et al., 2008; Maestrelli et al., 2015) to solid dispersions (Kamada et al., 2002; Xi et al., 2005), mini-tablets (Gazzaniga et al., 1994) and microparticle-based tablets (El-Gibaly, 2002).

This study aimed at (I) developing a ketoprofen colonic drug delivery system, $\mathrm{pH}$ and time dependent, by double-coating: the first step was compression-coating of ketoprofen mini-tablet cores (IR-tablets) with a layer based on a matrix-forming polymer (HPMC) and the second step was film-coating of the compression-coated tablets with an enteric outer film based on EL55 (Eudragit ${ }^{\mathbb{R}}$ L 30D-55), a methacrylic polymer. One of the greatest challenges for formulation scientists is to succeed obtaining the desired in vivo release profile and site specificity for a formulation previously characterized in vitro. There is a need of in vivo studies, especially of studies conducted on humans, therefore other objectives of our work were to (II) study the pharmacokinetics of the system in healthy human volunteers, and to (III) compare the in vitro-in vivo release of ketoprofen.

\section{MATERIAL AND METHODS}

\section{Material}

Ketoprofen (SIMS, Italy), was used as model drug. Lactose monohydrate for direct compression - Ludipress (BASF, Germany); microcrystalline cellulose PH 102 (Pharma, Germany); polyvinylpyrrolidone (PVP) K30 Kollidon K30 (BASF, Germany); sodium starch glycolate (JRS Pharma, Germany); hydroxypropylmethylcellulose (HPMC) - Methocel K100M (Colorcon, UK); silicon dioxide - Aerosil 200 (Degussa, Germany); magnesium stearate (Merck, Germany); EL55 (Evonik, Germany); Opadry II Orange (Colorcon, UK). All other chemicals were of analytical grade.

\section{Preparation of the colonic delivery system}

\section{Preparation of IR-tablets}

IR-tablets were prepared by wet granulation. The formula is presented in Table I. The blend of ketoprofen, lactose and $75 \%$ sodium starch glycolate was granulated with an alcoholic solution of PVP K30 15\%, then the granules were dried, sieved and evaluated in terms of flow and granulometric characteristics. Before compression, the difference of $25 \%$ sodium starch glycolate and the lubricants were added. The IR-tablets (weight $20 \mathrm{mg}, 17.2$ $\mathrm{mg}$ ketoprofen/tablet) were prepared using an eccentric tablet press (Korsch EK0, Germany), equipped with a 3 $\mathrm{mm}$ diameter concave punch. IR-tablets were evaluated for weight variation, desagregation, hardness, friability, content uniformity and percentage of drug release in 15 min according to European Pharmacopoeia (PhEur) $8^{\text {th }}$ edition methods.

TABLE I - Composition of IR-tablets

\begin{tabular}{lcc}
\hline Constituent & mg/IR-tablet & $\mathbf{\%}$ \\
\hline Ketoprofen & 17.2 & 86.00 \\
Lactose monohydrate DC & 0.40 & 2.00 \\
Sodium starch glycolate & 1.40 & 7.00 \\
Polyvinylpyrrolidone K30 & 0.40 & 2.00 \\
Silicon dioxide & 0.10 & 0.50 \\
Magnesium stearate & 0.30 & 1.50 \\
Talc & 0.20 & 1.00 \\
\hline Total & 20.00 & 100.00 \\
\hline
\end{tabular}

IR-tablets - mini-tablets with immediate release.

Compression-coating with time-dependent layer IR-tablets were coated by compression with a 
powder mixture containing HPMC K100M as matrixforming polymer. The same eccentric tablet press was used, equipped with a $7 \mathrm{~mm}$ diameter concave punch. The core tablets were coated by compression with 220 mg coating mixture (Table II). About $50 \%$ of the coating powder mixture was placed in the die cavity. The core tablet was then placed in the center of the die cavity, which was filled with the remainder of the coating powder mixture and was compressed around the core tablets. The final mass of the tablets was $240 \mathrm{mg}$. The prepared compression-coated ketoprofen tablets were tested for weight variation, hardness, and friability.

TABLE II - Composition of the powder mixture for compressioncoating

\begin{tabular}{lcc}
\hline Constituent & mg/tablet & \% \\
\hline Lactose monohydrate DC & 190.30 & 86.50 \\
HPMC K100M & 22.00 & 10.00 \\
Silicon dioxide & 1.10 & 0.50 \\
Magnesium stearate & 2.20 & 1.00 \\
Opadry II Orange & 4.40 & 2.00 \\
\hline Total & $\mathbf{2 2 0 . 0 0}$ & $\mathbf{1 0 0 . 0 0}$ \\
\hline
\end{tabular}

Film-coating with $\mathrm{pH}$-dependent layer

The compression-coated tablets were subsequently film-coated in a coating pan with an enterosoluble polymer: EL55, obtaining the CR-tablets. Table III shows the coating formula of the compression-coated tablets and the working conditions of the coating process. CR-tablets are shown schematically in Figure 1. After the coating, the tablets were maintained in a stability chamber (Binder, Germany) for $15 \mathrm{~h}$, at $40{ }^{\circ} \mathrm{C}$ and $20 \%$ relative humidity in order to stabilize the polymer film (curing).

\section{In vitro drug release study}

Ketoprofen release from CR-tablets was assessed by dissolution testing using the PhEur dissolution tester, apparatus I (rotating basket) (Pharma Test PT-DT7, Pharma Test, Germany) at a rotation speed of $50 \mathrm{rpm}$ and $500 \mathrm{~mL}$ of dissolution fluid at $37.0 \pm 0.5^{\circ} \mathrm{C}$. $\mathrm{HCl}$ $0.1 \mathrm{~N}$ ( $\mathrm{pH} 1.2$ ) was used as dissolution medium for $2 \mathrm{~h}$, followed by phosphate buffer ( $\mathrm{pH} \mathrm{6.8)} \mathrm{for} \mathrm{another} 3 \mathrm{~h}$, and finally, by phosphate buffer ( $\mathrm{pH} 7.4)$ until the end of $24 \mathrm{~h}$ in order to simulate the $\mathrm{pH}$ in different parts of the gastrointestinal tract (Crcarevska, Dodov, Goracinova, 2008; Meissner et al., 2007; Yehia et al., 2009). Samples of $5 \mathrm{ml}$ were withdrawn at $0.5,1,2,3,4,5,6,8,10,12$, 16,20 and $24 \mathrm{~h}$ time intervals and replaced with an equal volume of medium. The dissolution study was performed in triplicate. The concentration of dissolved ketoprofen was assayed by HPLC. The chromatographic conditions, adapted from a published method (Özlü et al., 2005) and used in a previous study (Hales et al., 2015), were: Agilent HPLC system (Agilent 1100 series, Agilent Technologies, SUA) equipped with a UV/Vis detector; stationary phase: Phenomenex Gemini C18 column (100 mm x 3 $\mathrm{mm}, 3 \mu \mathrm{m})$; mobile phase: acetonitrile:phosphoric acid

TABLE III - Film-coating formula and working conditions

\begin{tabular}{|c|c|c|c|}
\hline \multirow{5}{*}{ Film-coating formula } & \multicolumn{2}{|c|}{ Constituent } & \multirow{2}{*}{$\begin{array}{c}\text { Constituent quantity (\%) } \\
87.5\end{array}$} \\
\hline & Core & Compression-coated tablets & \\
\hline & Film layer & Eudragit ${ }^{\circledR}$ L 30D-55 & 9.0 \\
\hline & & Triethyl citrate & 1.0 \\
\hline & & Talc & 2.5 \\
\hline \multirow{10}{*}{ Working conditions } & \multicolumn{2}{|l|}{ Parameter } & Value \\
\hline & \multicolumn{2}{|c|}{$\overline{\text { Batch size }(\mathrm{g})}$} & 230 \\
\hline & \multicolumn{2}{|c|}{ Nozzle diameter $(\mathrm{mm})$} & 0.8 \\
\hline & \multicolumn{2}{|c|}{ Atomization pressure (atm) } & 2.6-2.8 \\
\hline & \multicolumn{2}{|c|}{ Nozzle flow rate (g/min) } & 7 \\
\hline & \multicolumn{2}{|c|}{ Inlet air temperature $\left({ }^{\circ} \mathrm{C}\right)$} & $35-40$ \\
\hline & \multicolumn{2}{|c|}{ Outlet air temperature $\left({ }^{\circ} \mathrm{C}\right)$} & $28-34$ \\
\hline & \multicolumn{2}{|c|}{ Pre-heating of the tablets (min) } & 10 \\
\hline & \multicolumn{2}{|c|}{ Spraying duration (min) } & 40 \\
\hline & \multicolumn{2}{|c|}{ Post-coating drying in coating pan (min) } & 10 \\
\hline
\end{tabular}




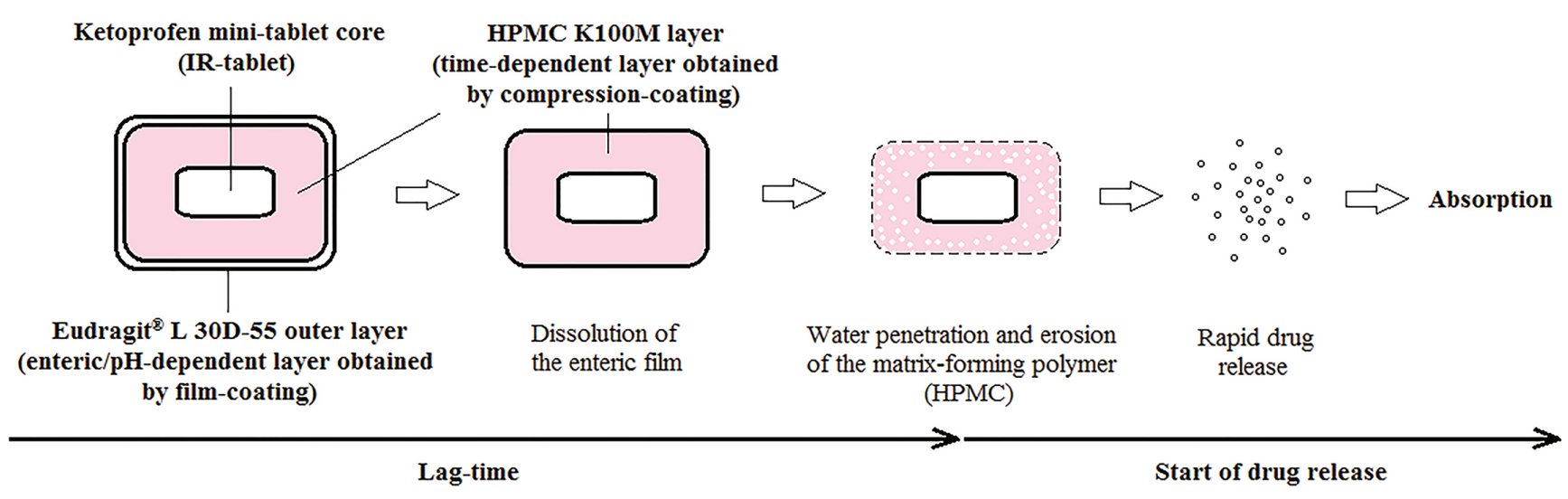

FIGURE 1 - Design of compression-coated tablets for colonic release (CR-tablets) and expected drug release behavior.

solution $0.1 \%(60: 40)$, isocratic elution; flow: $1 \mathrm{~mL} / \mathrm{min}$; temperature: $22{ }^{\circ} \mathrm{C}$; wavelength: $260 \mathrm{~nm}$ (UV); pressure: 222 bars; retention time: $1.05 \mathrm{~min}$; injection volume: $10 \mu \mathrm{L}$.

\section{In vivo drug availability testing}

The purpose of this part of the study was to assess the in vivo absorbtion of ketoprofen from IR-tablets and CR-tablets, and compare the results obtained with the ones achieved in the in vitro release study.

\section{Subjects}

Six healthy, non-smoking, caucasian volunteers aged between 28 and 33 years were enrolled in the study. The study was conducted according to the principles of the Declaration of Helsinki (1964) and its amendments and Good Clinical Practice rules. The clinical study protocol was reviewed and approved by the Ethics Committee of the University of Medicine and Pharmacy "Iuliu Hațieganu", Cluj-Napoca, Romania. The volunteers were informed about possible risks and adverse effects of the drug, and written informed consent was obtained from each subject prior to enrollment. The health condition of each volunteer was assessed prior to the inclusion in the study.

\section{In vivo pharmacokinetics study design}

The study was designed as a cross-over, randomized study that consisted of two periods. During period 1, volunteers received a single oral dose of $103.2 \mathrm{mg}$ ketoprofen from IR-tablets or CR-tablets (6 IR-tablets or 6 CR-tablets). During period 2, the volunteers received the formulation they did not receive in period 1 . Between the two periods, a 6-day wash-out period was introduced in order to allow the elimination of drug from the body. The drugs were administered in the morning, following an overnight fast (12 h), with at least $150 \mathrm{ml}$ water. Following drug administration, the volunteers were allowed to drink water starting $2 \mathrm{~h}$ after dosing. Standardized meals were provided 3-h, 6-h and 10-h after drug administration.

\section{Analysis of plasma samples}

During each study period, venous blood $(3 \mathrm{ml})$ was drawn into heparinized tubes before dosing (time 0 ) and at the following times: $0.5,1,1.5,2,2.5,3,4,6,8$, 10,12 and $24 \mathrm{~h}$ after drug administration. The separated plasma was stored at $-20^{\circ} \mathrm{C}$ until analysis. Ketoprofen plasma concentrations were determined by a validated HPLC method with UV detection. The calibration curve for ketoprofen was linear between 153.2-19155.0 ng/ml. The chromatographic conditions were: Agilent HPLC system equipped with a UV/Vis detector; stationary phase: Zorbax SB-C ${ }_{18}$ column (100 mm x 3 mm, $\left.3.5 \mu \mathrm{m}\right)$; mobile phase: acetonitrile:trifluoracetic acid solution $0.1 \%$ (45:55), isocratic elution; flow: $0.9 \mathrm{~mL} / \mathrm{min}$; temperature: $35^{\circ} \mathrm{C}$; wavelength: $257 \mathrm{~nm}$ (UV); injection volume: $4 \mu \mathrm{L}$.

\section{Pharmacokinetic and statistical analysis}

Non-compartmental pharmacokinetic (PK) analysis was performed to determine the pharmacokinetic parameters of ketoprofen: maximum plasma concentration $\left(\mathrm{C}_{\max }, \mathrm{ng} / \mathrm{ml}\right)$, time to reach the peak plasma concentration $\left(\mathrm{t}_{\max }, \mathrm{h}\right)$, area under the concentration-time curve from time 0 to time of last quantifiable concentration $\left(\mathrm{AUC}_{0-\mathrm{t}}\right)$, area under the concentration-time curve from time 0 to infinity $\left(\mathrm{AUC}_{0-\infty}\right)$, elimination rate constant $\left(\mathrm{k}_{\mathrm{el}}\right)$, half-life $\left(\mathrm{t}_{1 / 2}\right)$, mean residence time (MRT). The apparent cumulative absorption amount of ketoprofen was calculated by using deconvolution methodology. Analysis of variance (ANOVA) was used to compare the calculated pharmacokinetic parameters of ketoprofen for 
the two periods, using general linear model procedures, in which the sources of variation were the formulation and the subject. All pharmacokinetic and statistical analyses were performed using Phoenix WinNonlin 6.3 (Pharsight, SUA) software.

\section{RESULTS}

\section{The pharmacotechnical properties of granules, IR-tablets and compression-coated tablets}

The ability of a powder to flow is evidenced by the determination of the compresibility index and Hausner ratio, which are measures of the propensity of a powder to be compressed and which allow an assessment of the relative importance of interparticulate interactions. Table IV shows the values of Hausner ratio, Carr's index and particle size. Carr's index (compresibility index) was in the range $11-15 \%(14.70 \%)$, indicating good flow. Similarly, Hausner ratio value was between 1.12-1.18 (1.17), which indicated low interparticle friction. The size of the granules was $154.94 \mu \mathrm{m}$ with a variation of $46.60 \%$, which showed a satisfactory homogeneity of the granules in terms of particle size. IR-tablets were analysed using standard pharmacotechnical methods for tablets in PhEur $8^{\text {th }}$ edition and the pharmacotechnical results obtained are presented in Table IV. IR-tablets met the PhEur $8^{\text {th }}$ edition requirements: they had good mass uniformity, short disintegration time, low friability, good hardness, good content uniformity and very good percentage of ketoprofen dissolved in $15 \mathrm{~min}$. Also, the pharmacotechnical results obtained after compression- coating of IR-tablets (cores) with HPMC K100M are presented in Table IV. According to the obtained results, compression-coated tablets presented good values for weight variation, friability, resistance to crushing, which were within the compendial limits.

\section{In vitro drug release}

Dissolution testing of colon delivery systems has usually been conducted in fluids simulating the $\mathrm{pH}$ in the gastric and intestinal environment, for transit times that the colon delivery system could encounter in vivo. Therefore, the release study of CR-tablets was performed in $\mathrm{HCl} 0.1 \mathrm{M}(\mathrm{pH} 1.2)$ for $2 \mathrm{~h}$, then in phosphate buffer $0.05 \mathrm{M}$ (pH 6.8) for $3 \mathrm{~h}$, followed by phosphate buffer $0.05 \mathrm{M}(\mathrm{pH} 7.4)$ until the end of $24 \mathrm{~h}$. The release profile of ketoprofen from CR-tablets, in dissolution media that simulated different portions of the digestive tract, is presented in Figure 2, together with the release profile of ketoprofen from IR-tablets. In CR-tablets, the enteric polymer, EL55, was able to prevent drug release in the simulated gastric fluid: ketoprofen was not detected in the first $2 \mathrm{~h}$ at $\mathrm{pH}$ 1.2. The efficiency of the enteric coating film was also observed while changing $\mathrm{HCl}$ medium with phosphate buffer ( $\mathrm{pH}$ 6.8) inside the vessels; the tablets maintained their shape and the weight gain did not exceed $5 \%$ after being maintained in acidic medium for $2 \mathrm{~h}$. Due to the fact that EL55 is soluble at $\mathrm{pH}>5.5$ (in the upper gastrointestinal tract), ketoprofen could have been released after polymer's dissolution, but the HPMC layer delayed additionally the drug release, the first concentration of ketoprofen being detected after 6

TABLE IV - Characterization of granules, IR-tablets and compression-coated tablets

\begin{tabular}{llccc}
\hline & Flow properties & \multicolumn{3}{c}{ Values } \\
\cline { 2 - 5 } $\begin{array}{l}\text { Characterization of } \\
\text { granules }\end{array}$ & Hausner ratio & & 1.17 & \\
& Carr's index & & 14.70 & \\
& Granules size $(\mu \mathrm{m})$ & & 454.94 & \\
& CV $(\%)$ & $\mathbf{n}$ & IR-tablets & $\begin{array}{c}\text { Compression- } \\
\text { coated tablets }\end{array}$ \\
\hline & Test & 20 & $20.61 \pm 0.38$ & $240.55 \pm 1.43$ \\
\cline { 2 - 5 } $\begin{array}{l}\text { Characterization } \\
\text { of IR-tablets and } \\
\text { compression-coated } \\
\text { tablets }\end{array}$ & Weight variation $(\mathrm{mg} \pm \mathrm{SD})$ & 6 & $8.33 \pm 1.36$ & - \\
& Disintegration time $(\mathrm{s} \pm \mathrm{SD})$ & $6.5 \mathrm{~g}$ & 0.215 & 0.200 \\
& Friability $(\%)$ & 10 & $31.40 \pm 3.53$ & $259.00 \pm 8.30$ \\
& Hardness (Newton $\pm \mathrm{SD})$ & 10 & $93.89 \pm 1.33$ & - \\
\hline
\end{tabular}

IR-tablets - mini-tablets with immediate release; $\mathrm{CV}$ - coefficient of variation; $\mathrm{SD}$ - standard deviation. 
h. Moreover, ketoprofen percentages were insignificant between $6 \mathrm{~h}$ and $8 \mathrm{~h}(2.1-4.3 \%)$, but they increased suddenly and reached the maximum after $12 \mathrm{~h}(85.2 \%)$. Ketoprofen release from IR-tablets in neutral medium (phosphate buffer, pH 6.8) occured fast, 92.24\% ketoprofen being dissolved after $15 \mathrm{~min}$.

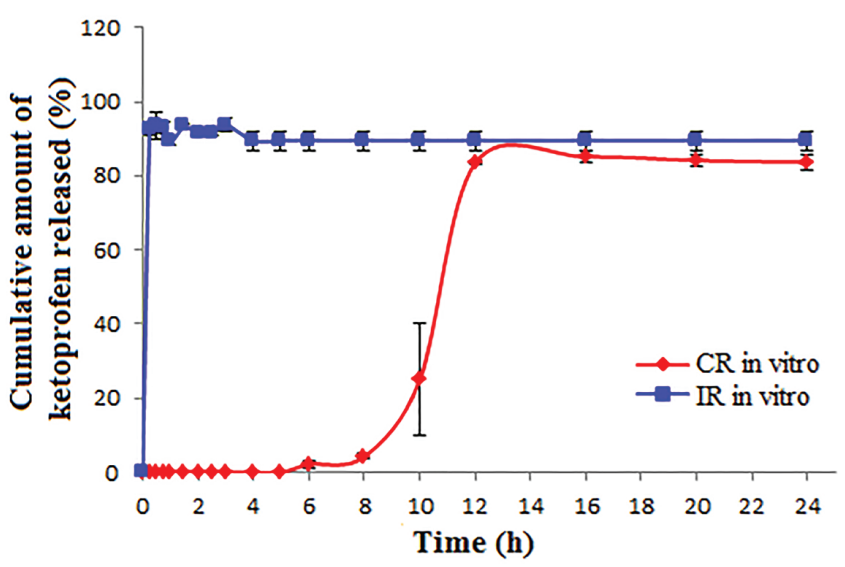

FIGURE 2 - Ketopofen release from IR-tablets $(n=3)$ - in phosphate buffer ( $\mathrm{pH}$ 6.8) for $24 \mathrm{~h}$ - and CR-tablets $(\mathrm{n}=3)$, in $\mathrm{HCl}(\mathrm{pH} 1.2$ ) for $2 \mathrm{~h}$, followed by phosphate buffer ( $\mathrm{pH}$ 6.8) for $3 \mathrm{~h}$ and phosphate buffer ( $\mathrm{pH}$ 7.4) for the next $19 \mathrm{~h}$. IR-tablets mini-tablets with immediate release; CR-tablets - compressioncoated tablets for colonic release.

\section{Pharmacokinetic and statistical analysis}

The mean plasma concentration-time profiles for ketoprofen following the administration of IR-tablets and CR-tablets are shown in Figure 3. The graph illustrates clearly the difference between the two formulations, the maximum plasma concentration was lower and the time to reach the peak plasma concentration was longer for CR-tablets, which demonstrates the fact that the release starts after a lag time, compared to the immediate release of IR-tablets.

The mean pharmacokinetic parameters of ketoprofen obtained after the administration of IR-tablets and CRtablets, as well as the statistical test results, are presented in Table V.

The statistical analysis of $\mathrm{C}_{\max }$ values obtained for the oral administration of $103.2 \mathrm{mg}$ ketoprofen as two different formulations (IR-tablets and CR-tablets) showed significant differences between the mean values obtained for the two formulations. The highest maximum concentration was obtained for IR-tablets ( 9549.50 $\pm 2156.12 \mathrm{ng} / \mathrm{mL}$ ). For CR-tablets, the maximum concentration obtained represented half of the one of IRtablets $(4920.33 \pm 1626.71 \mathrm{ng} / \mathrm{mL})$. The statistical analysis of $\mathrm{t}_{\max }$ values obtained for the oral administration of 103.2 mg ketoprofen as IR-tablets and CR-tablets showed also

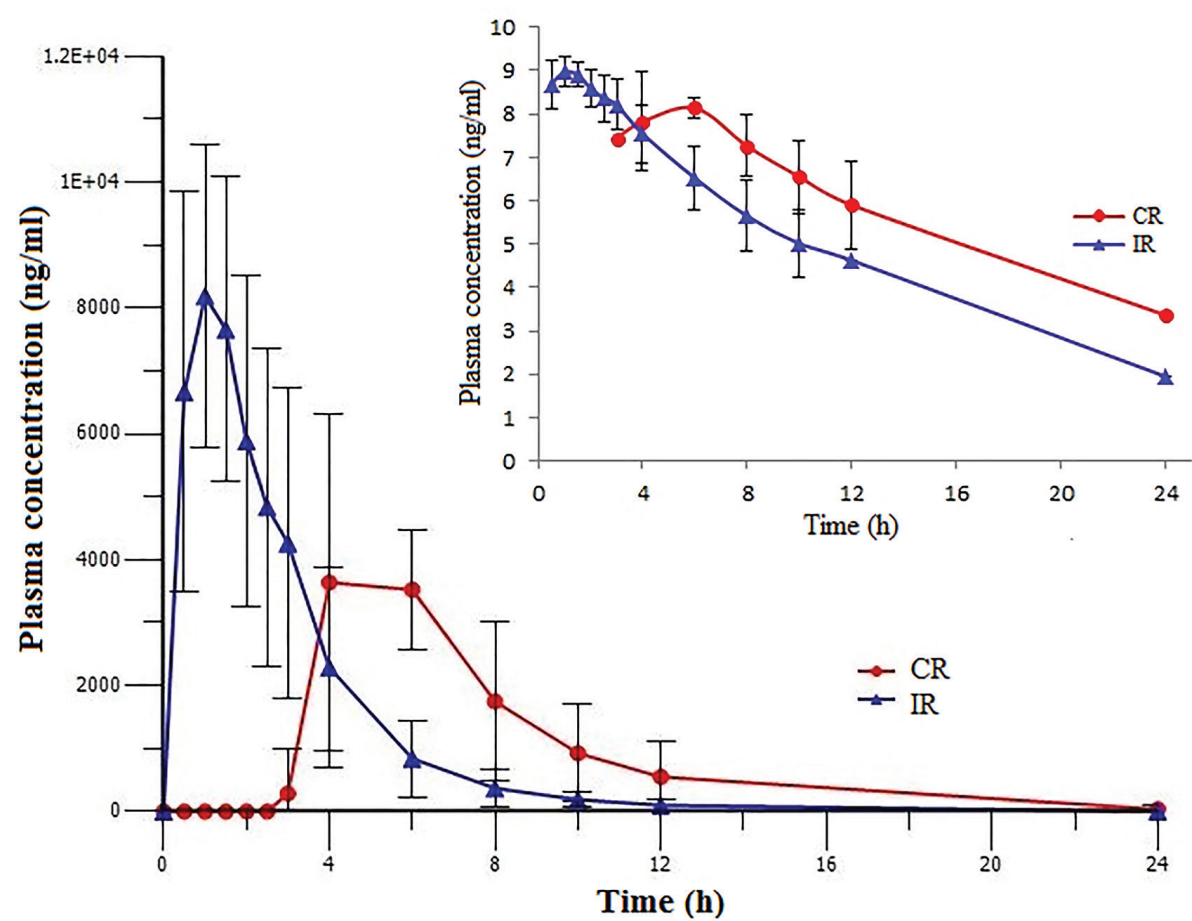

FIGURE 3 - Mean \pm SD plasma concentration-time curves of ketoprofen following the administration of IR-tablets and CR-tablets $(\mathrm{n}=6)$. Inset: semi-logarithmic presentation. IR-tablets - mini-tablets with immediate release; CR-tablets - compression-coated tablets for colonic release. 
Formulation, preparation and in vitro-in vivo evaluation of compression-coated tablets for the colonic-specific release of ketoprofen

TABLE V - Mean \pm SD pharmacokinetic (PK) parameters of ketoprofen in 6 healthy volunteers following the administration of IR-tablets and CR-tablets, respectively

\begin{tabular}{lccc}
\hline $\begin{array}{l}\text { PK parameter } \\
(\text { mean } \pm \text { SD) }\end{array}$ & \multicolumn{2}{c}{ Formulation } & p-value*, ANOVA \\
\cline { 2 - 3 } & $9549.50 \pm 2156.12$ & $4920.33 \pm 1626.71$ & 0.0003 \\
\hline $\mathrm{C}_{\max }(\mathrm{ng} / \mathrm{mL})$ & $1.33 \pm 0.88$ & $5.33 \pm 1.63$ & 0.0005 \\
$\mathrm{t}_{\max }(\mathrm{h})$ & $26301.22 \pm 8978.19$ & $22036.78 \pm 7873.03$ & 0.0788 \\
$\mathrm{AUC}_{0-\mathrm{t}}(\mathrm{ng} * \mathrm{~h} / \mathrm{mL})$ & $26730.15 \pm 9137.55$ & $22121.58 \pm 7773.11$ & 0.0668 \\
$\mathrm{AUC}_{0-\infty}(\mathrm{ng} * \mathrm{~h} / \mathrm{mL})$ & $0.37 \pm 0.10$ & $0.29 \pm 0.11$ & 0.0720 \\
$\mathrm{k}_{\mathrm{el}}(1 / \mathrm{h})$ & $1.99 \pm 0.52$ & $2.64 \pm 0.71$ & 0.0720 \\
$\mathrm{t}_{1 / 2}(\mathrm{~h})$ & $4302.17 \pm 1535.21$ & $5187.93 \pm 1927.48$ & 0.0788 \\
$\mathrm{Cl}(\mathrm{mL} / \mathrm{h})$ & $2.51 \pm 0.61$ & $7.07 \pm 1.35$ & 0.0000 \\
$\mathrm{MRT}(\mathrm{h})$ & &
\end{tabular}

IR-tablets - mini-tablets with immediate release; CR-tablets - compression-coated tablets for colonic release; *Statistically significant when $p<0.05$.

significant differences between the mean values obtained for both formulations. For IR-tablets, peak plasma concentration was achieved after $1.33 \pm 0.88 \mathrm{~h}$, which means that the drug release occurred immediately after administration and the absorption took place rapidly. After oral administration, CR-tablets reached peak concentration at $5.33 \pm 1.63 \mathrm{~h}$, which showed that the designed system was able to delay the drug release. Between the $\mathrm{AUC}_{0-\infty}$ obtained after administration of IR-tablets (26730.15 \pm $9137.55 \mathrm{ng} * \mathrm{~h} / \mathrm{mL}$ ) and the area under the curve obtained after administration of CR-tablets (22121.58 \pm 7773.11 $\mathrm{ng} * \mathrm{~h} / \mathrm{mL}$ ), there was no statistically significant difference. The parameters used to characterize the elimination of ketoprofen were the elimination rate constant, the half-life and the apparent clearance. The elimination rate constant of ketoprofen showed a value of $0.29 \pm 0.11 \mathrm{~h}^{-1}$ for the CR-tablets compared to $0.37 \pm 0.10 \mathrm{~h}^{-1}$ for the IR-tablets, indicating a lower elimination rate for the colonic release system, although the difference was not statistically significant $(\mathrm{p}>0.05)$. The mean half-life of ketoprofen was $2.64 \pm 0.71 \mathrm{~h}$ for the CR-tablets compared to $1.99 \pm$ $0.52 \mathrm{~h}$ for the IR-tablets. The elimination of ketoprofen with similar rate $(p>0.05)$ following the administration of the two formulations can also be observed from the comparison of clearance values: $4302.17 \pm 1535.21$ $\mathrm{ml} / \mathrm{h}$ for IR-tablets and $5187.93 \pm 1927.48 \mathrm{ml} / \mathrm{h}$ for CR-tablets. MRT of ketoprofen in the body presented a highly significant difference $(\mathrm{p}<0.001)$ between the two formulations: $2.51 \pm 0.61 \mathrm{~h}$ for the IR-tablets and 7.07 $\pm 1.35 \mathrm{~h}$ for the CR-tablets. Since MRT is dependent on the rate at which the drug will move through a person's body, this difference indicates the fact that CR-tablets are a delayed release system.

\section{In vitro-in vivo comparison}

The apparent cumulative amount of ketoprofen absorbed following the administration of IR-tablets and CR-tablets to 6 healthy volunteers is presented in Figure 4. The differences between the two formulations are the time to acquire the maximum quantity absorbed and the value of the maximum quantity absorbed. The average apparent cumulative amount of ketoprofen absorbed was $100 \%$ for the IR-tablets, while for the CR-tablets the mean value was $83.94 \pm 15.74 \%$.

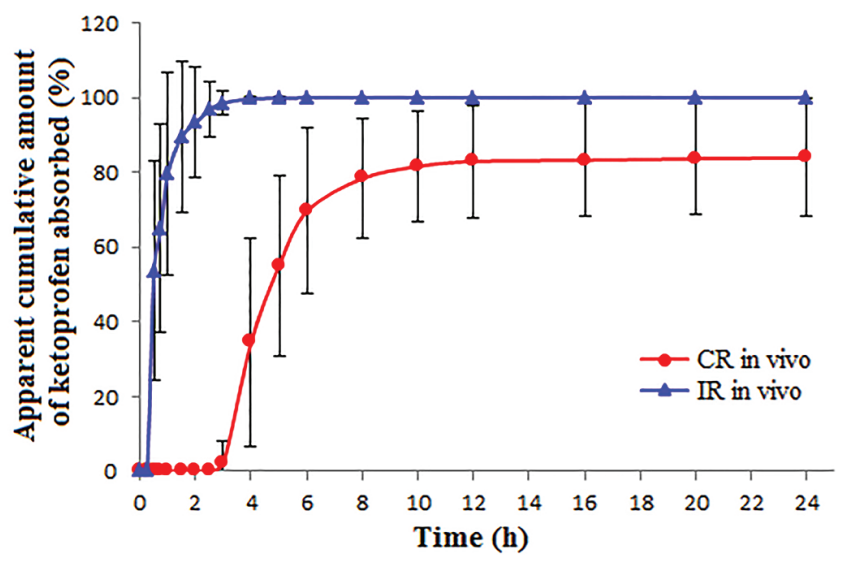

FIGURE 4 - Apparent cumulative amount of ketoprofen absorbed following the administration of IR-tablets and CRtablets $(n=6)$. IR-tablets - mini-tablets with immediate release; CR-tablets - compression-coated tablets for colonic release.

These results can be compared to the ones obtained during the in vitro dissolution studies (Figure 2). In the case of IR-tablets, approximately all amount of 
ketoprofen $(92.23 \pm 1.60 \%)$ dissolved after $15 \mathrm{~min}$, and then the percentage increased slightly within $3 \mathrm{~h}$ up to a maximum of $93.73 \pm 1.72 \%$. Similarly, in the case of the in vivo study of the same formulation, the absorption of ketoprofen was significant after $30 \min (53.70 \pm 29.24 \%)$ and the maximum amount absorbed was on average nearly $100 \%$. The CR-tablets prevented the absorption of ketoprofen for $5 \mathrm{~h}$ during the in vitro dissolution study, the first detectable concentrations (starting with the $6 \mathrm{~h}$ sample) being small initially, increasing sharply only after $10 \mathrm{~h}$ and reaching the maximum $(85.16 \pm 1.73 \%)$ after 16 $\mathrm{h}$. The same system tested by the in vivo study was able to prevent the absorption for $3 \mathrm{~h}$, then the concentrations increased significantly in the range of $4-8 \mathrm{~h}$ and reached a maximum $(83.94 \pm 15.74 \%)$ after $24 \mathrm{~h}$.

\section{DISCUSSION}

In the present study, in order to verify that the characteristics evaluated by pharmacotechnical and in vitro studies for the CR-tablets designed in this work may be confirmed by in vivo studies, the system was evaluated on human subjects. The first steps were to determine different pharmaceutical properties of granules and tablets to verify their compliance with pharmacopoeia standards. Granules presented good flow and had a satisfactory homogeneity in terms of particles size. IR-tablets were found uniform in weight variation, disintegration time, friability, hardness and drug content, and allowed ketoprofen's almost complete dissolution in approximately 15 min. Compression-coated tablets' evaluation showed also uniformity of weight variation, friability and hardness.

The dissolution studies revealed that CR-tablets were able to provide chronopharmaceutical colonspecific ketoprofen release. EL55 outer film prevented water penetration to the HPMC K100M inner coat during stomach transit, the film being intact after $2 \mathrm{~h}$ in acidic environment, but dissolving after placing the CR-tablets in alkaline $\mathrm{pH}$. In alkaline medium, the hydrophilic inner coat started to absorb water and to form a porous structure, but the drug release did not start immediately after the enteric polymer's dissolution due to the high viscosity of the swollen gel which was able to control the drug diffusion. Similar results were observed in a previous study, which evaluated the influence of different types and concentrations of HPMC and enteric polymers on ketoprofen's release (Hales et al., 2015). The system succeeded not only to delay ketoprofen release in the stomach and small intestine, but also to release a significant amount of drug at the targeted colon site. Therefore, IR-tablets provided desirable attributes according to the dissolution study: $6 \mathrm{~h}$ lag time and $85.2 \%$ drug release. Other groups of researchers found similar results: Patel et al. (2016) coated ketoprofen core tablets using a mixture of Eudragit ${ }^{\circledR}$ S100 and Eudragit ${ }^{\circledR}$ L100 and obtained compression-coated tablets with $4 \mathrm{~h}$ lag time and more than $80 \%$ drug release; Devi and Sharma (2015) prepared compression-coated ketoprofen tablets using amylose/ethyl cellulose mixture and observed that during $5 \mathrm{~h}$ the system released less than $20 \%$ ketoprofen, but finally reached $76.31 \%$ drug release; Alencar et al. (2017) found that Eudragit ${ }^{\circledR} \mathrm{S} 100$ coated pellets compressed into tablets were able to release less than $20 \%$ ketoprofen for $4 \mathrm{~h}$, but to allow the release of approximately $90 \%$ of the drug until the end of the dissolution study.

The pharmacokinetic evaluation showed clear differences between IR-tablets and CR-tablets. $\mathrm{C}_{\max }$ values were lower for CR-tablets compared to IR-tablets, which is common for colon drug delivery systems since the main functions of the large bowel are water and electrolytes absorption, deposit and elimination of faeces, and not absorption of drugs and nutrients. Also, the colonic contents become more viscous with progressive absorption of water during colon transit, which causes a reduced dissolution rate, slow diffusion of dissolved drug through the mucosa and therefore, low amount of drug absorbed (Challa, Vynala, Allam, 2011). These findings were similar to the ones observed with some indomethacin colon targeted double-film-coated mini-tablets (Tomuţă et al., 2010).

Also, the time needed to reach $\mathrm{C}_{\text {max }}\left(\mathrm{t}_{\max }\right)$ was higher for CR-tablets $(5.33 \pm 1.63 \mathrm{~h})$ than for IR-tablets $(1.33$ $\pm 0.88 \mathrm{~h}$ ). Pišlar et al. (2015) found that the median of gastric emptying, small intestinal transit and colon arrival times of subjects where the first meal intake was at $4 \mathrm{~h}$ post-dose was 35,215 , and 254 min, respectively. Also, other papers stated that stomach transit time is usually less than $1 \mathrm{~h}$ in fasting state (Challa, Vynala, Allam, 2011). Therefore, in the case of IR-tablets, the results indicate that the absorption started in the stomach, as the first plasma concentrations appeared after $15 \mathrm{~min}$, and occurred mainly in the small intestine. For CR-tablets, the time to reach peak plasma concentration was around $5 \mathrm{~h}$, which means that drug release occurred mainly in the large intestine. CR-tablets did not release the drug for approximately $3 \mathrm{~h}$, which means that ketoprofen was not released in the stomach, nor in the upper and middle parts of the small intestine. The delayed release was due to the EL55 film that prevented activation of the system in the stomach and, afterwards to the HPMC K100M 10\% layer which eroded with a lag time of about $3 \mathrm{~h}$. Similar studies that investigated pharmacokinetic parameters following 
colon drug delivery systems administration to dogs showed similar $\mathrm{t}_{\max }$ values: approximately $5 \mathrm{~h}$ for diltiazem hydrochloride and phenylpropanolamine hydrochloride enteric coated timed-release press-coated tablets (Fukui et al., 2000), $5.20 \pm 1.10 \mathrm{~h}$ for metoprolol tartrate oral sustained-release drug delivery system (Nakamura, Nara, Akiyama, 2006) or $5.3 \pm 0.9 \mathrm{~h}$ for 5-aminosalicylic acid pressure-controlled colon delivery capsules (Takaya et al., 1998). A pharmacokinetic study conducted on human volunteers showed also a similar $\mathrm{t}_{\max }$ of $5.7 \pm 1.92 \mathrm{~h}$ for indomethacin double-film-coated mini-tablets (Tomuţă et al., 2010).

Comparing the $\mathrm{AUC}_{0-\infty}$ of IR-tablets $(26730.15 \pm$ $9137.55 \mathrm{ng} * \mathrm{~h} / \mathrm{mL})$ and CR-tablets (22121.58 \pm 7773.11 $\mathrm{ng} * \mathrm{~h} / \mathrm{mL}$ ), one could observe that the colonic release formulation had a relative bioavailability of approximately $85 \%$ compared to the immediate release formulation, therefore it could be considered that the absorption of the two formulations was close in terms of quantity absorbed (less than $15 \%$ difference). Similar pharmacokinetic studies also found no clear difference in AUC between immediate and colonic release dosage forms (Ishibashi et al., 1999), whereas others observed low bioavailability and incomplete absorption from colonic drug delivery systems due to the reduced water content in the lower intestine which tended to decrease drug absorption (Tomuţă et al., 2010).

The MRT value for CR-tablets was $7.07 \pm 1.35 \mathrm{~h}$, which was 2.8 times longer than that for IR-tablets (2.51 $\pm 0.61 \mathrm{~h}$ ). The value of MRT ratio between CR-tablets and IR-tablets was similar to the MRT ratio obtained in other studies: 2.8 for colon-specific double-compression coated mini-tablets (Vemula, 2015).

The apparent cumulative amount of ketoprofen absorbed presented similar values in vitro-in vivo, both for the IR-tablets $(92.2 \pm 1.5 \%$ versus $100 \%)$ and CR-tablets $(85.16 \pm 1.73 \%$ versus $83.94 \pm 15.74 \%)$. The time necessary to reach the maximum quantity absorbed was similar in vitro-in vivo (15 min-1 h) in the case of IR-tablets. The lag time presented by CR-tablets both in vitro and in vivo (3-6 h) can be correlated with the colon arrival time mentioned in the literature (3-4 h) (Pišlar et al., 2015). This means that the lag time corresponds to the transit time of the stomach and the small intestine and that the release of ketoprofen started in the last part of the ileum or in the colon, the majority of drug release happening in the colon. Other studies, which worked on establishing an in vitro-in vivo correlation, established the relationship between in vitro and in vivo parameters through a correlation coefficient $\mathrm{r}^{2}$ (Vemula, 2015). However, of all the data obtained in this study, it can be observed that the developed colonic system using time-dependent and $\mathrm{pH}$-dependent techniques managed to prevent release of ketoprofen in the stomach and small intestine and allowed releasing a significant amount in the colon.

\section{CONCLUSION}

Herein, a compression-coated and film-coated tablet system for colonic release was designed and successfully achieved the aims of accomplishing the colon-specific release of ketoprofen. The controlled release colon delivery system was developed by compression-coating with a time-dependent polymer (HPMC K100M) and filmcoating with a pH-dependent polymer (Eudragit ${ }^{\circledR}$ L 30D55). In vitro studies showed that the pharmaceutical system was able to prevent drug release in acidic medium $(0.1 \mathrm{M}$ $\mathrm{HCl}$ solution, $\mathrm{pH}$ 1.2) for $2 \mathrm{~h}$ and also in neutral medium (phosphate buffer, $\mathrm{pH}$ 6.8) for another $3 \mathrm{~h}$, the drug release starting after $6 \mathrm{~h}$ (in phosphate buffer, $\mathrm{pH}$ 7.4) and reaching a maximum in approximately $16 \mathrm{~h}$. According to the data obtained for the in vivo pharmacokinetic study, the absorption of ketoprofen from compression-coated tablets for colonic release occured after a lag time of $3 \mathrm{~h}$ (meaning that the drug release started in the last part of the ileum or in the colon), and the maximum plasma concentration was reached after $5.33 \mathrm{~h}$ (meaning that the greatest part of the drug was released in the large intestine). In conclusion, this system is a suitable approach to acquire colon-specific drug release of ketoprofen.

\section{ACKNOWLEDGEMENTS}

This research did not receive any specific grant from funding agencies in the public, commercial, or not-forprofit sectors.

\section{REFERENCES}

Alencar RG, de Oliveira AC, Lima EM, da Cunha-Filho MSS, Taveira SF, Marreto RN. Compacted multiparticulate systems for colon-specific delivery of ketoprofen. AAPS PharmSciTech. 2017. DOI: 10.1208/s12249-016-0700-2. Epub ahead of print.

Biswas N, Guha A, Sahoo RK, Kuotsu K. Pulse release of doxazosin from hydroxyethylcellulose compression coated tablet: mechanistic and in vivo study. Int J Biol Macromol. 2015;72:537-543.

Challa T, Vynala V, Allam KV. Colon specific Drug Delivery Systems: A review on primary and novel approaches. Int J Pharm Sci Rev Res. 2011;7:171-181. 
Crcarevska MS, Dodov MG, Goracinova K. Chitosan coated $\mathrm{Ca}$-alginate microparticles loaded with budesonide for delivery to the inflamed colonic mucosa. Eur J Pharm Biopharm. 2008;68(3):565-578.

Devi N, Sharma M. Statistical optimization of compression coated ketoprofen tablet using amylose/ethyl cellulose mixture for colonic delivery. J Appl Pharm Res. 2015;3(1):10-17.

El-Gibaly I. Oral delayed-release system based on Zn-pectinate gel microparticles as an alternative carrier to calcium pectinate beads for colonic delivery. Int J Pharm. 2002;232(1-2):199-211.

Fukui E, Miyamura N, Kobayashi M. An in vitro investigation of the suitability of press-coated tablets with hydroxypropylmethylcellulose acetate succinate (HPMCAS) and hydrophobic additives in the outer shell for colon targeting. J Control Release. 2001a;70(1-2):97-107.

Fukui E, Miyamura N, Kobayashi M. Effect of magnesium stearate or calcium stearate as additives on dissolution profiles of diltiazem hydrochloride from press-coated tablets with hydroxypropylmethylcellulose acetate succinate in the outer shell. Int J Pharm. 2001b;216(1-2):137-146.

Fukui E, Miyamura N, Uemura K, Kobayashi M. Preparation of enteric coated timed-release press-coated tablets and evaluation of their function by in vitro and in vivo tests for colon targeting. Int J Pharm. 2000;204(1-2):7-15.

Fukui E, Miyamura N, Yoneyama T, Kobayashi M. Drug release from and mechanical properties of press-coated tablets with hydroxypropylmethylcellulose acetate succinate and plasticizers in the outer shell. Int J Pharm. 2001;217(1-2):33-43.

Gazzaniga A, Iamartino P, Maffione G, Sangalli ME. Oral delayed-release system for colonic specific delivery. Int J Pharm. 1994;108(1):77-83.

Hales D, Iovanov RI, Achim M, Leucuța SE, Muntean DM, Vlase L, et al. Development of a $\mathrm{pH}$ and time controlled release colon delivery system obtained by compression-coating and film-coating. Farmacia. 2015;63(4):510-517.

Hashem FM, Shaker DS, Nasr M, Saad IE, Ragaey R. Guar gum and hydroxy propyl methylcellulose compressed coated tablets for colonic drug delivery: in vitro and in vivo evaluation in healthy human volunteers. Drug Discov Ther. 2011;5(2):90-95.
Ishibashi T, Hatano H, Kobayashi M, Mizobe M, Yoshino H. In vivo drug release behavior in dogs from a new colon-targeted delivery system. J Control Release. 1999;57(1):45-53.

Kamada M, Hirayama F, Udo K, Yano H, Arima H, Uekama $\mathrm{K}$. Cyclodextrin conjugate-based controlled release system: repeated- and prolonged-releases of keptoprofen after oral administration in rats. J Control Release. 2002;82(2-3):407-416.

Maestrelli F, Zerrouk N, Cirri M, Mennini N, Mura P. Microspheres for colonic delivery of ketoprofen-hydroxypropyl$\beta$-cyclodextrin complex. Eur J Pharm Sci. 2008;34(1):1-11.

Maestrelli F, Zerrouk N, Cirri M, Mura P. Comparative evaluation of polymeric and waxy microspheres for combined colon delivery of ascorbic acid and ketoprofen. Int J Pharm. 2015;485(1-2):365-373.

Meissner Y, Ubrich N, El Ghazouani F, Maincent P, Lamprecht A. Low molecular weight heparin loaded pH-sensitive microparticles. Int J Pharm. 2007;335(1-2):147-153.

Nakamura K, Nara E, Akiyama Y. Development of an oral sustained release drug delivery system utilizing $\mathrm{pH}$-dependent swelling of carboxyvinyl polymer. J Control Release. 2006;111(3):309-315.

Özlü C, Basan H, Șatana E, Ertaș N, Göğer NG. Quantitative determination of ketoprofen in gels and ampules by using flowinjection UV spectrophotometry and HPLC. J Pharm Biomed Anal. 2005;39(3-4):606-611.

Patel H, Pandey S, Patel V, Shah R, Tiwari S. Pulsatile release of ketoprofen from compression coated tablets using Eudragit ${ }^{\circledR}$ polymers. Int J Pharm Pharm Sci. 2016;8(2):224-229.

Pišlar M, Brelih H, Mrhar A, Bogataj M. Analysis of small intestinal transit and colon arrival times of non-disintegrating tablets administered in the fasted state. Eur J Pharm Sci. 2015;75:131-141.

Shohin IE, Kulinich JI, Ramenskaya GV, Vasilenko GF. Evaluation of in vitro equivalence for drugs containing BCS Class II compound ketoprofen. Dissolut Technol. 2011;26-29.

Sinha VR, Mittal BR, Bhutani KK, Kumria R. Colonic drug delivery of 5-fluorouracil: an in vitro evaluation. Int J Pharm. 2004;269(1):101-108. 
Takaya T, Niwa K, Muraoka M, Ogita I, Nagai N, Yano R, et al. Importance of dissolution process on systemic availability of drugs delivered by colon delivery system. J Control Release. 1998;50(1-3):111-122.

Tomuţă I, Vlase L, Popa A, Leucuţa SE. In vitro - in vivo evaluation of a novel drug delivery system for colonic targeting. Farmacia. 2010;58(3):368-377.

Veerareddy PR, Vemula SK. Formulation, evaluation and pharmacokinetics of colon targeted pulsatile system of flurbiprofen. J Drug Target. 2012;20(8):703-714.

Vemula SK. Formulation and pharmacokinetics of colon-specific double-compression coated mini-tablets: Chronopharmaceutical delivery of ketorolac tromethamine. Int J Pharm. 2015;491(12):35-41.

Vonica AL, Tomuță I, Leucuța SE. Experimental design for the screening of three types of coating polymers for metoprolol minitablets with pulsatile release. Farmacia. 2011;6(59):742749.
Xi MM, Zhang SQ, Wang XY, Fang KQ, Gu Y. Study on the characteristics of pectin-ketoprofen for colon targeting in rats. Int J Pharm. 2005;298(1):91-97.

Yehia SA, Elshafeey AH, Sayed I, Shehata AH. Optimization of Budesonide Compression-Coated Tablets for Colonic Delivery. AAPS PharmSciTech. 2009;10(1):147-157.

Yiyun C, Tongwen X, Rongqinag F. Polyamidoamine dendrimers used as solubility enhancers of ketoprofen. Eur J Med Chem. 2005;40(12):1390-1393.

Received for publication on $07^{\text {th }}$ January 2017 Accepted for publication on $06^{\text {th }}$ July 2017 